\title{
Foeto-maternal outcome in oligohydramnios
}

\author{
Jil Karia, Pallavi Ninama, Pinal Pateliya, Ronak Karnavat*
}

Department of Obstetrics and Gynaecology, GMERS Medical College and Hospital, Sola, Ahmedabad, Gujarat, India

Received: 06 December 2021

Accepted: 04 January 2022

\author{
*Correspondence: \\ Dr. Ronak Karnavat, \\ E-mail: rdkarnavat43@gmail.com
}

Copyright: () the author(s), publisher and licensee Medip Academy. This is an open-access article distributed under the terms of the Creative Commons Attribution Non-Commercial License, which permits unrestricted non-commercial use, distribution, and reproduction in any medium, provided the original work is properly cited.

\section{ABSTRACT}

Background: Oligohydramnios is defined as an amniotic fluid index (AFI) of $\leq 5 \mathrm{~cm}$. AFI is calculated by adding the depth in centimetres of the largest vertical pocket in each of four equal uterine quadrants in ultrasonography. We aimed to evaluate the predictive value of amniotic fluid index (AFI) $(\leq 5 \mathrm{~cm})$ for mode of delivery, associated complications, perinatal outcome, birth weight, meconium staining and APGAR scores.

Methods: This was a prospective study of 100 antenatal women who presented at our antenatal OPD at GMERS Medical College and Civil Hospital, Sola, Ahmedabad, Gujarat with gestational age between 34 and 41 weeks over a 1-year duration from 2020 to 2021. The women's history was taken, clinical examination done, and AFI was measured, and results were tabulated.

Results: Prevalence was most among the 20-30 age group. Most patients delivered vaginally. Anaemia and gestational hypertension were the most common associated complications. There was no neonatal death in this study. No significant correlation was found between oligohydramnios and low birth weight babies.

Conclusions: Oligohydramnios has a significant correlation with caesarean section for foetal distress and low birth weight babies.

Keywords: AFI, APGAR scores, Birth weight, Caesarean delivery, Meconium staining, Oligohydramnios

\section{INTRODUCTION}

The American College of Obstetricians and Gynaecologists (ACOG) has defined oligohydramnios as amniotic fluid index (AFI) $\leq 5 \mathrm{~cm}\left(<10^{\text {th }}\right.$ centile) or maximum vertical pocket devoid of umbilical cord or foetal limbs measuring $<2 \mathrm{~cm}^{1}$

Clinical estimation of amniotic fluid volume (AFV) is an important part of foetal assessment as variation in its amount has been related to a variety of pregnancy complications. Amniotic fluid provides a protective milieu for the growing foetus, cushioning it against mechanical and biological injury. ${ }^{2,3}$ It protects the foetus against trauma, allows space for foetal movement, enables foetal swallowing (necessary for gastrointestinal tract development), and prevents cord compression. ${ }^{4}$ Quantification of amniotic fluid is an important component of the biophysical profile in ultrasound evaluation of foetal well-being, especially in the third trimester. ${ }^{5}$ Antenatal tests use amniotic fluid volume as a fundamental assessment of chronic in-utero stress. Ultrasound being a non-invasive test is ideal for application on a large scale and can be used frequently for repeat AFV determination in the case of suspected abnormalities. $^{3}$

The risk factors for oligohydramnios are foetal, chromosomal, or structural anomalies (renal anomalies), rupture of the membrane, intrauterine infection, use of certain drugs (PG inhibitors, ACE inhibitors), postmaturity, intrauterine growth restriction (IUGR) and hypertensive disorders. ${ }^{6}$

Links have been found between decreased amniotic fluid volume and stillbirths, foetal anomaly, abnormal FHR tracings in labour, increased caesarean sections for foetal distress, and possibly foetal acidosis. ${ }^{2}$ In the present study, 
amniotic fluid quantification was done by the fourquadrant technique as described by Phelan et al to determine AFI and we sought to determine if an antepartum AFI of $5 \mathrm{~cm}$ or less is a predictor of adverse perinatal outcome in terms of meconium staining, mode of delivery, birth weight, low APGAR scores. ${ }^{3,7}$

\section{METHODS}

This was a prospective study carried out at the GMERS Medical College and Civil Hospital, Sola, Ahmedabad, Gujarat after approval from the ethics committee. The study participants included 100 antenatal women selected from those who presented in our OPD with gestational age between 34 and 41 weeks, admitted for delivery over a duration of 1 year from 2020 to 2021 . Informed consent was taken from all patients.

\section{Inclusion criteria}

Antenatal women with AFI $<5 \mathrm{~cm}$ and delivered at our hospital; women with a singleton, term non-anomalous foetus with intact membranes at the time of antepartum testing.

\section{Exclusion criteria}

Gestational age <34 weeks and >41 weeks; women with premature rupture of membranes; with known foetal or chromosomal anomalies; intrauterine death; placental anomalies; multiple pregnancy; uterine anomalies.

After admission, comprehensive history taking and clinical examination were performed to assess causative factors and associated complications. History regarding antenatal drug intake was taken. Ante partum foetal surveillance reports, investigations and other obstetric factors were also deciding factors for labour induction and elective/emergency caesarean section.

Amniotic fluid index was determined using the Phelan's technique within 7 days of delivery or at the on-set of labour after informed written consent. ${ }^{4}$ Non stress test (NST) was performed for all patients. Women were selected based on their AFI (done within 7 days of delivery).

Once oligohydramnios was confirmed by measuring AFI, routine management in the form of rest in left lateral position, oral and intravenous hydration was given and simultaneously evaluated for underlying etiological factor and corrected if identified. Ante partum foetal surveillance was done by USG, NST and modified biophysical profile. Umbilical artery (UA) Doppler studies were also done if required.

A note was made of meconium staining of amniotic fluid, the ultimate mode of delivery, birth weight, APGAR score at 1 and 5 minutes and NICU admission measured at the time of birth.

\section{RESULTS}

Oligohydramnios was observed mainly in the age group of 20-30 years. No significant difference was found in terms of parity. 37-40 weeks showed the maximum incidence of oligohydramnios. Anaemia and gestational hypertension were the most common associated complications in this study.

\section{Table 1: Maternal demographic and obstetric} characteristics.

\begin{tabular}{|lll|}
\hline \multicolumn{2}{|c|}{ AFI $\leq \mathbf{5}(\mathbf{n = 1 0 0})$} & Percentage \\
\hline Maternal age & & \\
\hline$<20$ years & 21 & 21 \\
\hline 20-30 years & 57 & 57 \\
\hline$>30$ years & 22 & 22 \\
\hline Gravidity & & \\
\hline Primigravida & 43 & 43 \\
\hline Multigravida & 57 & 57 \\
\hline Gestational age (weeks) & & \\
\hline $34-37$ & 33 & 33 \\
\hline $37-40$ & 42 & 42 \\
\hline $40-41$ & 25 & 25 \\
\hline Associated complications & \\
\hline Gestational hypertension & 17 & 17 \\
\hline Anaemia & 23 & 23 \\
\hline Fever & 7 & 7 \\
\hline IUGR & 11 & 11 \\
\hline Malpresentation & 9 & 9 \\
\hline Prolonged labour & 18 & 18 \\
\hline $\begin{array}{l}\text { Post-partum } \\
\text { haemorrhage }\end{array}$ & 4 & 4 \\
\hline
\end{tabular}

Table 2: Intrapartum observations.

\begin{tabular}{|c|c|c|}
\hline & $\begin{array}{l}\text { AFI } \leq 5 \\
(n=100)\end{array}$ & Percentage \\
\hline \multicolumn{3}{|c|}{ Foetal heart rate (FHR) tracing } \\
\hline Normal & 66 & 66 \\
\hline $\begin{array}{l}\text { Abnormal }(<110 / \mathrm{bpm} \text { or } \\
>160 / \mathrm{bpm})\end{array}$ & 34 & 34 \\
\hline \multicolumn{3}{|l|}{ Liquor } \\
\hline Clear & 63 & 63 \\
\hline Meconium stained & 37 & 37 \\
\hline \multicolumn{3}{|l|}{ Mode of delivery } \\
\hline Vaginal delivery & 74 & 74 \\
\hline Spontaneous & 28 & 28 \\
\hline Induced & 46 & 46 \\
\hline Instrumental delivery & 01 & 01 \\
\hline $\begin{array}{l}\text { Lower segment caesarean } \\
\text { section (LSCS) }\end{array}$ & 26 & 26 \\
\hline
\end{tabular}

Only 34\% developed abnormal FHR tracing. MSL was observed in $37 \%$ cases. $74 \%$ patients delivered vaginally, whereas LSCS was done in $26 \%$. 
Table 3: Perinatal outcome.

\begin{tabular}{|lll|}
\hline & AFI $\leq \mathbf{5}(\mathbf{n = 1 0 0})$ & Percentage \\
\hline APGAR score & & \\
\hline 1 minute $<7$ & 7 & 7 \\
\hline 5 minutes $<7$ & 4 & 4 \\
\hline Birth weight & \\
\hline$\leq 2.5 \mathrm{~kg}$ & 39 & 39 \\
\hline$>2.5 \mathrm{~kg}$ & 61 & 61 \\
\hline Admission to NICU & \\
\hline Yes & 41 & 41 \\
\hline No & 59 & 59 \\
\hline
\end{tabular}

Only $7 \%$ of neonates had and APGAR score $<7.59 \%$ of neonates weighed $>2.5 \mathrm{~kg}$. $41 \%$ required NICU admission.

\section{DISCUSSION}

Al Chalabi et al, reported that women in the low AFI group had increased rate of LSCS. ${ }^{8}$

Manzanares et al, found that women in the low AFI group when induced found to have increased incidence of LSCS and instrumental delivery. ${ }^{8}$ According to Manzanares et al, irregular FHR tracing is found to be significantly higher in the oligohydramnios group when induced. ${ }^{8}$

Medel et al, reported that, there is no significant difference in the meconium-stained liquor in between low AFI and NL group. ${ }^{8}$

Singhal et al study significantly higher induction of labour was seen in low AFI group $72 \%$ as compared to control group $12 \% .^{9}$

Mathuriya et al study $65 \%$ of the study cases and only $10 \%$ of controls underwent LSCS. ${ }^{9}$

In Ranjita et al study caesarean section rate was $54 \%$ in the oligohydramnios group as compared to control group $26 \% .^{10}$

Chaudhary et al study reported $51 \%$ underwent LSCS in cases, while $22 \%$ underwent LSCS in control. ${ }^{10}$

Chauhan et al in 1999 found that both antepartum and intrapartum oligohydramnios was associated with an increased risk of caesarean delivery for foetal distress and 5-min Apgar score <7. ${ }^{11}$

Ek and colleagues randomly assigned 54 patients beyond 40 weeks to either induction of labour or expectant management. No differences were found for any important maternal or neonatal outcome.

Leeman and Almond noted that isolated term oligohydramnios has not been shown to be associated with poor maternal or foetal outcomes.
Rossi and Prefumo concluded that IO in uncomplicated term pregnancies is associated with an approximately 2fold increase in operative delivery because of NRFHR. ${ }^{12}$

In Donald et al, the incidence of oligohydramnios was $60 \%$ in primigravida whereas it was $43 \%$ in the present study. ${ }^{13}$

Sir Gangaram Hospital study showed $68 \%$ vaginal deliveries in induced patients of oligohydramnios and $32 \%$ by caesarean section which is comparable to our study. ${ }^{14}$

Manzanares et al shows $84 \%$ vaginal deliveries in induced patients of oligohydramnios and $16 \%$ by caesarean section. ${ }^{15}$

\section{CONCLUSION}

Oligohydramnios was prevalent in $57 \%$ of women in the age group of 20-30 years. The gestational age group of 3740 weeks showed to have maximum frequency of oligohydramnios. Anaemia and gestational hypertension were the most common associated complications, followed by IUGR, malpresentation and fever. Prolonged labour was observed in some cases. Abnormal FHR was developed by $34 \%$ of patients. $37 \%$ had meconium-stained liquor. Emergency LSCS was done in $26 \%$ of patients, while $74 \%$ successfully delivered vaginally. There was no neonatal death in this study as $41 \%$ of the neonates admitted in NICU were discharged, while 59\% required no NICU admission. No significant correlation was found between oligohydramnios and low birth weight babies.

Funding: No funding sources

Conflict of interest: None declared

Ethical approval: The study was approved by the Institutional Ethics Committee

\section{REFERENCES}

1. Phalen JP, Smith CV, Broussard P, Small M. Amniotic fluid volume assessment using the fourquadrant technique in the pregnancy between 36 and 42 weeks gestation. J Reprod Med. 1987;32:601-4.

2. Underwood M, Gilbert W, Sherman M. Amniotic fluid: not just fetal urine anymore. J Perinatol. 2005;25:341-8.

3. Hebbar S, Rai L, Adiga P, Guruvare S. Reference ranges of amniotic fluid index in late third trimester of pregnancy: what should the optimal interval between two ultrasound examinations be? J Pregnancy. $2015 ; 319204$.

4. Fitzsimmons ED, Bajaj T. Embryology, Amniotic Fluid. In: StatPearls Treasure Island (FL): StatPearls Publishing; 2021.

5. Preboth M. ACOG guidelines on antepartum fetal surveillance. American College of Obstetricians and Gynecologists. Am Fam Physician. 2000;62(5):1184, 1187-8. 
6. Keilman C, Shanks AL. Oligohydramnios. In: StatPearls. Treasure Island (FL): StatPearls Publishing; 2021

7. Phelan JP, Ahn MO, Smith CV, Rutherford SE, Anderson E. Amniotic fluid index measurements during pregnancy. J Reprod Med Obstet Gynecol. 1987;32(8):601-4.

8. Rathod S, Samal SK. Evaluation of maternal and perinatal outcomes of induction in borderline oligohydramnios at term. J Clin Diagn Res. 2017;11(9):QC05-7.

9. Mashkaria AM, Patel BS, Shah AC, Jani SK, Patel VB, Patel AB, et al. Study of effects of oligohydramnios on perinatal outcome. Int J Reprod Contracept Obstet Gynecol. 2020;9:2525-9.

10. Sreelakshmi U, Bindu T, Subhashini T. Impact of oligohydramnios on maternal and perinatal outcome: a comparative study. Int J Reprod Contracept Obstet Gynecol. 2018;7(8):3205-11.

11. Chauhan SP, Sanderson M, Hendrix NW, Magann EF, Devoe LD. Perinatal outcome and amniotic fluid index in the antepartum and intrapartum periods: a meta-analysis. Am J Obstet Gynecol. 1999;181:14738.

12. Rossi AC, Prefumo F. Perinatal outcomes of isolated oligohydramnios at term and post-term pregnancy: a systematic review of literature with meta-analysis. Eur J Obstet Gynecol Reprod Biol. 2013;169:149-54.

13. Petrozella LN, Dashe JS, McIntire DD, Leveno KJ. Clinical significance of borderline amniotic fluid index and oligohydramnios in preterm pregnancy. Obstet Gynecol. 2011;117(2 Pt 1):338-42.

14. Umber A. Perinatal outcome in pregnancies complicated by isolated oligohydramnios at term. Ann King Edward Med Univ. 2009;15:35-7.

15. Manzanares S, Carrillo MP, González-Perán E, Puertas A, Montoya F. Isolated oligohydramnios in term pregnancy as an indication for induction of labor. J Matern Fet Neonat Med. 2007;20(3):221-4.

Cite this article as: Karia J, Ninama P, Pateliya P, Karnavat R. Foeto-maternal outcome in oligohydramnios. Int J Reprod Contracept Obstet Gynecol 2022;11:482-5. 